\title{
Viabilidade econômica da terceirização ou compra de frota de veículos para empresa de fertilizantes minerais
}

Economic feasibility of outsourcing or purchasing fleet of vehicles for a mineral fertilizer company

\author{
João Bosco Diniz ${ }^{*}$; Michel Augusto Santana da Paixão ${ }^{2}$
}

\footnotetext{
1* Poli/USP - Mestre em Engenharia Automotiva - R. Benedito A. Mariano, 160 - CEP 13272-093 - Valinhos (SP), Brasil <joaobosco27@hotmail.com>

${ }^{2}$ ESALQ - Doutorando em ciências econômicas - Av. Pádua Dias, 11 - São Dimas - CEP 13418-900 - Piracicaba (SP), Brasil
}

\section{Resumo}

A redução dos custos operacionais de frotas de veículos rodoviários no Brasil, bem como a realização de investimentos nessa área, são de extrema importância para a competitividade das empresas do setor. O objetivo deste estudo foi realizar uma análise de dados comparativos entre os custos de uma frota própria de uma empresa de fertilizantes minerais com a opção de frota terceirizada, utilizando o método de Valor Presente Líquido [VPL], descrevendo os procedimentos, e analisando os resultados para verificar qual opção geraria mais lucro para a empresa, sendo a escolha por frota própria a mais lucrativa.

Palavras chave: comparativo custos, comparativo rentabilidade, valor presente líquido

\begin{abstract}
The reduction of the operational costs of road vehicle fleets in Brazil, as well as the realization of investments in this area, are extremely important for the competitiveness of the companies in the sector. The objective of this study is to perform an analysis of comparative data between the costs of a company's own fleet of chemical fertilizers with the outsourced fleet option, using the Net Present Value [NPV] method, describing the procedures, and analyzing the results to verify which option generates more profit for the company, being the choice of own fleet much more profitable.
\end{abstract}

Key words: net present value, comparative of costs, comparative of profitability

\section{Introdução}

A terceirização, a qual inclui a decisão de internalização, não é só um fenômeno popular, mas é visto como uma das mais importantes estratégias de gerenciamento (Schniederjans et al., 2015).

De acordo com Lankford e Parsa (1999) a terceirização é definida como a compra de produtos ou serviços de fontes externas à organização. Para serviços, geralmente envolve a transferência aos fornecedores do controle operacional da atividade em questão.

Essa prática é motivada pela redução de custos e vantagens competitivas, que seriam custosas se pertencessem à própria organização. Assim, as empresas buscam a experiência e o conhecimento técnico de terceiros, ao invés de tentar atingir seus objetivos através de suas próprias competências (Lankford e Parsa, 1999). Nesse sentido, a terceirização de frotas tem sido uma opção para ganho de competitividade, através do aumento de produtividade nas atividades de infraestrutura da empresa.

Segundo Lankford e Parsa (1999), a terceirização pode ser uma vantagem quando os produtos ou serviços são produzidos de forma mais eficaz e eficiente por fornecedores externos.

Esta pesquisa objetiva avaliar, através de modelo quantitativo, a vantagem em termos de custos operacionais, da terceirização de frota em uma empresa de Uberaba, MG, que atua no mercado nacional, na produção e comercialização de fertilizantes minerais para a agricultura.

\section{Material e Métodos}

O objeto de estudo desse artigo consiste em uma empresa de fertilizantes minerais de propriedade limitada situada em Minas Gerais e que atende todo território nacional oferecendo diversos produtos para todo tipo de cultura, buscando atender e se adequar as necessidades do agronegócio brasileiro.

Assim, dentro dessa ótica de eficiência na gestão com o foco na atividade fim, tanto quanto na disponibilização de maiores recursos na produção, a empresa busca uma alternativa para gestão da frota de vinte e quatro veículos de suporte para seus representantes comerciais distribuídos nas regiões Norte, Nordeste e Centro-Oeste do Brasil.

Todos os dados coletados da empresa foram cedidos pelos gestores da empresa. A análise desse investimento deve proporcionar à empresa a possibilidade redução de custo operacional, melhorando seus resultados e trazendo mais competitividade no setor em que atua.

A princípio realizou-se um levantamento de dados junto aos proprietários da empresa, e, em seguida, a análise dos dados, fazendo a seleção, classificação e organização das informações aplicando em seguida a metodologia. 
Foram solicitadas cotações específicas às principais locadoras nacionais, e custo de manutenção e seguro baseados em informação cedida pela empresa. Valores de taxas e impostos, encargos e demais benefícios fiscais ou contábeis foram considerados conforme a legislação vigente.

A pesquisa se limitou a estudar a alternativa de terceirização de frota de veículos leves, utilizados no Departamento de Vendas e Marketing, onde foram excluídas quaisquer análises envolvendo os caminhões e outros veículos de suporte à produção, e, portanto, despesas com motoristas e mão de obra correlatas não são aplicáveis nesse estudo.

A terceirização de frotas se coloca mais como um serviço de gestão, enquanto que o "Leasing" se limita à uma operação financeira. O serviço de locação oferece a operação e gestão de transporte, licenciamento, manutenção, seguros, pneus, atendimento 24 horas, reboque e informação gerencial, enquanto que no "Leasing", continua a ser gerenciado pela própria empresa. Por essa razão a opção de "Leasing" não foi considerada nesse trabalho.

Devido às características do contrato de aluguel no serviço de terceirização de frotas, não foi considerada, neste trabalho, a análise de riscos para a empresa.

Considerou-se como terceirização de frota, o aluguel de uma frota de veículos leves para a empresa, com serviços de manutenção preventiva e corretiva, seguro, documentação, impostos e taxas, pneus, serviço de reboque com atendimento 24 horas em caso de pane ou sinistro, com direito a um veículo reserva.

No estudo de viabilidade econômica considerou-se o tempo médio pelo qual as locadoras costumam manter seus veículos. Não foram considerados nesse estudo, os custos de administração de frota, uma vez que esse serviço é parte da administração da empresa e o recurso humano não será dispensado no caso de terceirização.

Diferenças de consumo de combustível entre as frotas alugada e própria não foram reputadas, dada a complexidade dos fatores que devem ser considerados em sua análise (Diniz, 2009) ${ }^{1}$.

Para o método de viabilidade econômica, foi utilizado o Valor Presente Líquido [VPL]. A avaliação se baseou nos valores envolvendo a situação atual da empresa, a qual foi definida através das premissas apresentadas anteriormente. Assim foi verificado se os serviços terceirizados são mais ou menos, financeiramente, vantajosos quando comparados à operação de uma Frota Própria.
Segundo Bodie e Merton (1999), o VPL é o valor presente de todos os fluxos de caixa futuros, descontado o valor presente de todos os investimentos. Para Gitman (1997), a abordagem feita por comparação dos VPLs entre fluxos de caixa das alternativas de aquisição de bens, baseia-se no racionamento das alternativas de projetos envolvendo investimento de capital, o qual se fundamenta na utilização de valores presentes para escolher o projeto que vai maximizar a riqueza.

Para Gitman (1997), a Taxa Interna de Retorno [TIR] é a taxa de desconto que iguala o Valor Presente das entradas de caixa ao Valor Presente [VP] das saídas, isto é, a taxa de desconto que zera o VPL.

Em relação a qual indicador financeiro escolher como melhor entre a TIR ou o VPL, Gitman (1997) propõe o VPL, pois o mesmo mensura exatamente o maior retorno em unidades monetárias, dada uma taxa de oportunidade, enquanto que a TIR não fornece tal dimensão quantitativa referente ao montante monetário deste retorno, mas somente um referencial relativo ao investimento.

Essa abordagem foi utilizada por Lebo e Scott (2009) $)^{2}$ comparando as opções de "Leasing" e compra dos veículos de suporte da marinha americana, apresentada também por Brito et al. (2014), e defendida por Belfort $(2013)^{3}$ e Silva (2005) ${ }^{4}$.

Para Atkinson (1997), a análise "What-if" significa a exploração do efeito de uma mudança em um parâmetro sobre o resultado, e a Análise de Sensibilidade é a investigação do efeito de uma mudança em um parâmetro de decisão. Da mesma forma, Bodie e Merton (1999) afirmam que a Análise de Sensibilidade consiste em avaliar se o projeto ainda traz um resultado satisfatório mesmo que algumas variáveis fundamentais acabem assumindo valores diferentes dos presumidos, ou seja, a Análise de Sensibilidade é a análise do resultado de uma mudança em um parâmetro de decisão.

Dessa forma, foram feitas simulações de cenário, explorando até que ponto a variação das premissas mais importantes puderam implicar numa mudança da resultante das avaliações envolvidas na pesquisa, de maneira a atestar as condições da validade, ou não, da hipótese formulada sobre a viabilidade da terceirização de frota.

Foram assumidas as premissas de uma Taxa Mínima de Atratividade [TMA], utilizada no cálculo do VPL, como a taxa de aplicação em Certificado de Depósito Interbancário [CDI], anualizada em 09 de novembro de $2016(13,88 \%)(B C B, 2016)$.

\footnotetext{
${ }^{1}$ Diniz, J.B. 2009. Desenvolvimento e Validação de um Software para Simulação de Consumo de Combustível Veicular. Dissertação de Mestrado em Engenharia Automotiva. Escola Politécnica da Universidade de São Paulo. São Paulo, São Paulo, Brasil.

${ }^{2}$ Lebo, S. J.; Scott, R. M. 2009. Lease vs purchase analysis of alternative fuel vehicles in the United States Marine Corps. Dissertação de Mestrado em Gerenciamento Naval Postgraduate School, Monterrey, CA, Estados Unidos da América. Disponível em: < http://www.dtic.mil/dtic/tr/fulltext/u2/a514322.pdf >. Acesso em: 06 nov. 2016

${ }^{3}$ Belfort, C. 2013. Gestão de veículos leves: Uma avaliação de custos ideais na companhia Vale S.A. em São Luís. Trabalho de conclusão de curso em Bacharel em Administração. Universidade Federal do Maranhão. São Luís, MA, Brasil.

${ }^{4}$ Silva, C. F. O. 2005. A manutenção de uma frota de veículos locados versus a compra de uma frota própria sob os aspectos financeiros. Trabalho de conclusão de curso em Bacharel em Administração. Universidade Federal do Rio Grande do Sul. Porto Alegre, RS, Brasil.
} 
Os valores de seguros e despesas com manutenção da frota foram fornecidos pela empresa e projetados para os anos subsequentes com a taxa média do Índice Nacional de Preços ao Consumidor [INPC] dos últimos três anos $(7,89 \%)$, calculado conforme dados fornecidos em IBGE (2016).

A taxa de depreciação do veículo foi de $20 \%$ ao ano, conforme legislação vigente, consultada em Receita Federal (2016 a).

O valor atual dos veículos foi definido conforme a tabela divulgada pela Fundação Instituto de Pesquisas Econômicas [FIPE] (2016), e para os anos subsequentes foi projetada a desvalorização com a taxa média do INPC dos últimos três anos $(7,89 \%)$.

Os valores referentes aos preços de aluguel foram cotados em uma empresa de locação do mercado, porém não constou a taxa de correção dos valores, então se assumiu a taxa média do INPC dos últimos três anos $(7,89 \%)$.

Os veículos escolhidos pela empresa e cotados, foram 22 caminhonetes de pequeno porte, com capacidade de carga de $500 \mathrm{~kg}$, e duas de grande porte, com capacidade de carga de uma tonelada. A locadora atrelou o valor do aluguel a um limite de rodagem de $2000 \mathrm{~km}$ mensais por veículo, e acima desse limite foi posto um adicional por quilômetro rodado. Esse adicional foi considerado no valor anual do aluguel, uma vez que a frota da empresa tem uma média de $6670 \mathrm{~km}$ mensais para as caminhonetes pequenas e $4135 \mathrm{~km}$ para as grandes.
O período do fluxo de caixa foi de três anos, conforme cotação da locadora. O Imposto de Renda Pessoa Jurídica [IRPJ] considerado foi calculado em 34\% (9\% Contribuição Social sobre Lucro Líquido [CSLL] somado os $25 \%$ IRPJ), conforme legislação vigente em Receita Federal (2016 b).

Os valores do Imposto sobre a Propriedade de Veículos Automotores [IPVA] foram calculados conforme Fazenda (2016), Seguro de Danos Pessoais Causados por Veículos Automotores de Via Terrestre [DPVAT] e Licenciamento foram obtidos no Departamento Estadual de Trânsito de São Paulo [Detran] (2016).

Considerou-se que a frota seria vendida pelo valor da Tabela FIPE (2016), para opção de terceirização, e o valor investido no mercado financeiro, obtendo $O$ rendimento da TMA, de onde se obteve o valor do Rendimento sobre o Investimento. Esse rendimento foi utilizado para abater parte do aluguel da frota.

\section{Resultados e Discussão}

A Tabela 1 mostra o modelo financeiro para o cálculo do VPL para a frota própria da empresa, num período de três anos. $\mathrm{O}$ valor considerado do investimento inicial, foi a soma do valor de cada veículo da frota na tabela FIPE (2016). O valor residual foi o valor calculado para venda da frota. O Custo se refere à Redução de IRPJ menos a soma das despesas.

Tabela 1. Modelo financeiro para cálculo de Valor Presente Líquido [VPL] da Frota Própria da empresa em estudo

\begin{tabular}{|c|c|c|c|c|}
\hline Despesas & & 2017 & 2018 & 2019 \\
\hline & 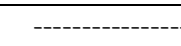 & - & -------------- & ----------- \\
\hline Impostos (IPVA*) & & $30.706,99$ & $28.284,21$ & $26.052,58$ \\
\hline Taxas (Licenciamento) & & $2.221,93$ & $2.397,24$ & $2.586,38$ \\
\hline Seguro Obrigatório (DPVAT**) & & $2.807,10$ & $3.028,58$ & $3.267,54$ \\
\hline Seguros & & $49.863,46$ & $53.797,68$ & $58.042,32$ \\
\hline Manutenção & & $11.450,37$ & $12.353,80$ & $13.328,51$ \\
\hline Depreciação & & $214.405,76$ & $190.570,78$ & $149.506,04$ \\
\hline Redução IRPJ*** & & $105.894,90$ & 98746,98 & $-181632,38$ \\
\hline Custo & & $8.845,06$ & $-1.114,53$ & $-284.909,72$ \\
\hline Investimento & 1.007.053,00 & & & \\
\hline Valor Residual & & & & $786.996,27$ \\
\hline Fluxo de Caixa & $-1.007 .053,00$ & $8.845,06$ & $-1.114,53$ & $502.086,55$ \\
\hline
\end{tabular}

Nota: * Imposto sobre a Propriedade de Veículos Automotores; ** Danos Pessoais Causados por Veículos Automotores de Via Terrestre; *** Imposto de Renda Pessoa Jurídica

Fonte: Resultados originais da pesquisa

A Tabela 2 mostra o modelo financeiro para o cálculo do VPL para a terceirização da frota, num período de três anos. O valor do investimento não foi considerado no cálculo do VPL, pois se assumiu que esse montante entrou como alavancagem financeira na empresa e não como investimento em frota de veículo. O custo, nesse caso, é zero, pois não há despesas com a frota. 
Tabela 2. Modelo financeiro para terceirização da frota da empresa em estudo

\begin{tabular}{|c|c|c|c|c|}
\hline Despesas & & 2017 & 2018 & 2019 \\
\hline & \multicolumn{4}{|c|}{ 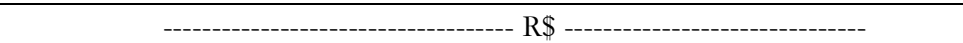 } \\
\hline Impostos (IPVA*) & & 0,00 & 0,00 & 0,00 \\
\hline Taxas (Licenciamento) & & 0,00 & 0,00 & 0,00 \\
\hline Seguro Obrigatório (DPVAT**) & & 0,00 & 0,00 & 0,00 \\
\hline Seguros & & 0,00 & 0,00 & 0,00 \\
\hline Manutenção & & 0,00 & 0,00 & 0,00 \\
\hline Custo & & 0,00 & 0,00 & 0,00 \\
\hline Rendimento sobre o Capital & & $141.177,47$ & $159.374,39$ & $161.900,12$ \\
\hline IRPJ sobre o investimento & & $28.235,49$ & $31.874,88$ & $32.380,02$ \\
\hline Rendimento Liquido de Capital & & $112.941,97$ & $127.499,51$ & $129.520,10$ \\
\hline Investimento & $1.007 .053,00$ & & & \\
\hline Redução IRPJ*** & & $-168.648,36$ & $187.458,50$ & $212.363,25$ \\
\hline Locação & & $-511.028,40$ & $-551.348,54$ & $-624.597,80$ \\
\hline Fluxo de Caixa & & $-566.734,79$ & $-236.390,53$ & $-282.714,45$ \\
\hline
\end{tabular}

Nota: * Imposto sobre a Propriedade de Veículos Automotores; ** Danos Pessoais Causados por Veículos Automotores de Via Terrestre; *** Imposto de Renda Pessoa Jurídica

Fonte: Resultados originais da pesquisa

Os resultados do modelo financeiro obtidos nessa pesquisa foram o VPL para a Frota Própria de $-\mathrm{R} \$$ 660178,83 e o VPL para a Frota Terceirizada de -R\$ 871366,09 , o que mostrou uma economia de 31,99\% em três anos, se fosse mantida a frota própria.

\section{Cenários e Simulações}

A fim de prover uma orientação estratégica para a empresa, no caso de flutuações nas premissas consideradas nessa pesquisa, foi realizada uma simulação com variações no valor mensal do aluguel dos veículos, na taxa de correção contratual, na TMA, na taxa de desvalorização dos veículos.

Conforme a Figura 1, considerando variação uniforme na taxa de desvalorização dos veículos entre 5 e 40\%, e variação distribuída normalmente da TMA, com desvio padrão de $1,39 \%$, obteve-se probabilidade de $87,86 \%$ de que a opção de frota própria ainda seja mais rentável que a frota terceirizada. Isso significa que mesmo com alta variação da taxa de desvalorização, a frota própria ainda se manteve como a melhor opção.

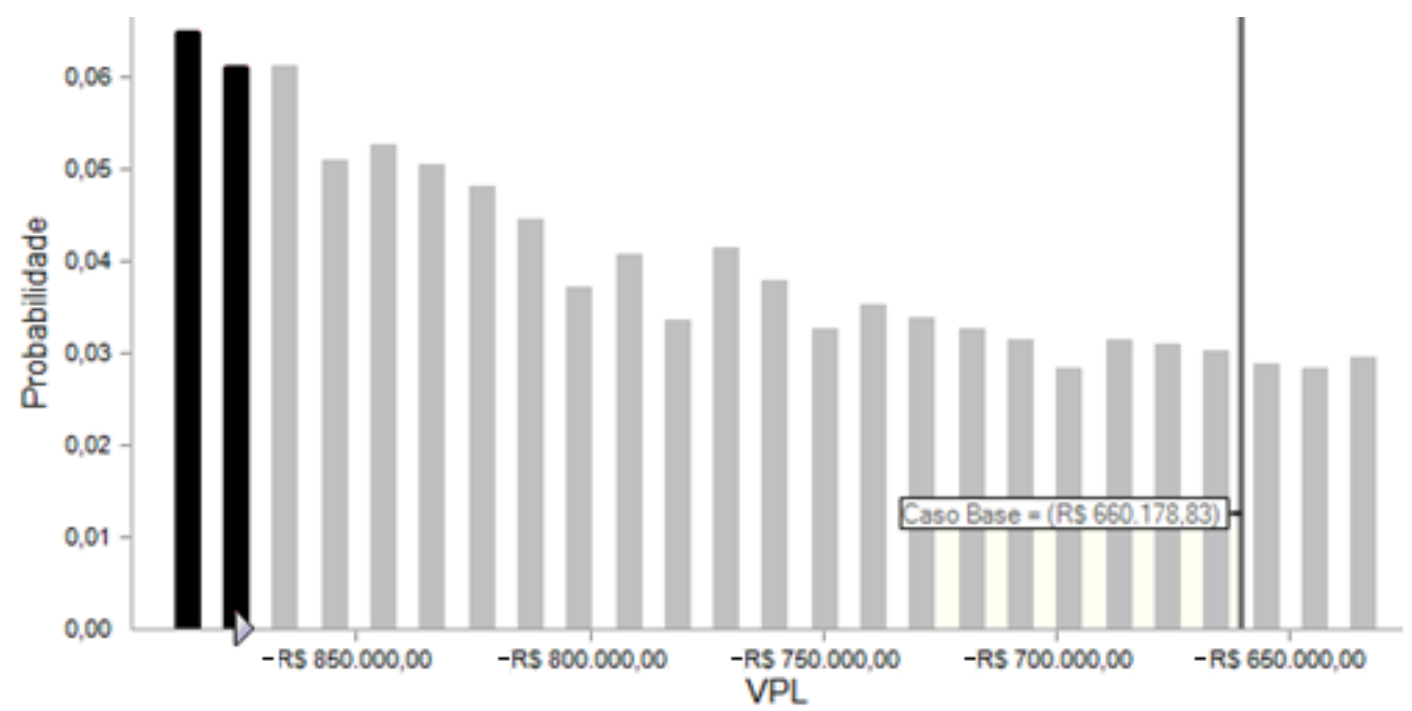

Figura 1. Valor Presente Líquido [VPL] considerando a variação na taxa de desvalorização dos veículos e variação da Taxa Mínima de Atratividade [TMA]

Fonte: Resultados originais da pesquisa 
A Figura 2 mostra a análise de sensibilidade do resultado do cálculo de VPL às variáveis TMA e Taxa de desvalorização dos veículos, indicando que a variação no preço de venda dos veículos afetou o resultado financeiro em 99,0\%, enquanto que a TMA foi responsável por apenas $1,0 \%$.
Para que a opção de frota própria possa ter o mesmo resultado financeiro da opção de frota terceirizada, seria necessário contar com uma desvalorização de 35,63\% no valor de venda dos veículos da frota, conforme Tabela 3.

Taxa de desvalorização

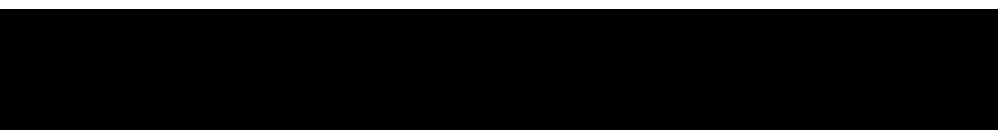

TMA
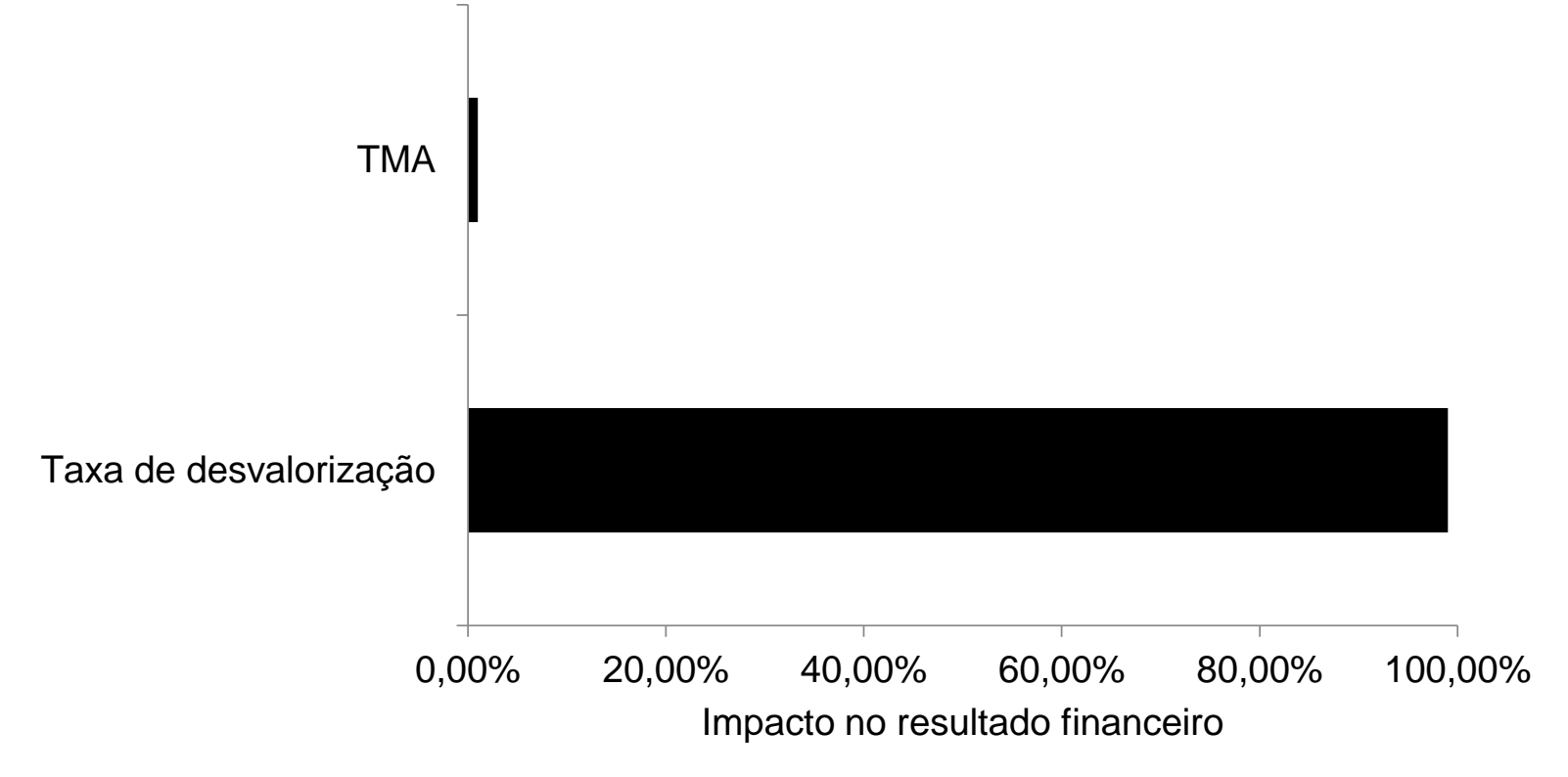

Figura 2. Impacto no resultado financeiro frente a variações na Taxa Mínima de Atratividade [TMA] e na taxa de desvalorização

Fonte: Resultados originais da pesquisa

Tabela 3. Valor objetivo da taxa de desvalorização para frota própria na empresa estudada

\begin{tabular}{lcc}
\hline & Objetivo & Variáveis de Decisão \\
\multicolumn{1}{c}{ Estatística } & Definir a meta Média VPL* & Taxa de desvalorização \\
\hline Média & - - $871.366,09$ & Ta \\
Desvio Padrão & $-871.366,09$ & 35,63 \\
\hline
\end{tabular}

Nota: * Valor Presente Líquido

Fonte: Resultados originais da pesquisa

A Figura 3 apresenta a análise de sensibilidade do resultado do cálculo de VPL às variáveis TMA e aluguel dos veículos, mostrando que a variação no preço do aluguel dos veículos afetou em 84,4\% o resultado financeiro, enquanto que a TMA foi responsável por $9,8 \%$. O Valor de locação de caminhonetes grandes teve uma influência menor, dado o número reduzido de veículos, enquanto a Taxa de correção contratual, em termos práticos, não ofereceu alteração nos resultados $(0,2 \%)$. Para que a terceirização da frota seja viável, o valor do aluguel da caminhonete pequena deve ser menor que $\mathrm{R} \$ 952,53$, conforme mostrou a simulação na Tabela 4. 


\section{Taxa de correção contratual Valor locação caminhonete grande TMA Valor locação caminhonete pequena $\begin{array}{llllll}0,0 \% & 20,0 \% & 40,0 \% & 60,0 \% & 80,0 \% & 100,0 \%\end{array}$ Impacto no resultado financeiro}

Figura 3. Impacto no resultado financeiro frente a variações na taxa de correção contratual, valor de locação da caminhonete grande, Taxa Mínima de Atratividade [TMA] e no valor da locação da caminhonete pequena

Fonte: Resultados originais da pesquisa

Tabela 4. Valor objetivo de aluguel de caminhonetes pequenas para frota terceirizada na empresa estudada

\begin{tabular}{|c|c|c|}
\hline & Objetivo & Variáveis de Decisão \\
\hline Estatística & Definir a meta Média VPL* $=-\mathrm{R} \$ 660.178,83$ & Valor Locação caminhonete pequena \\
\hline Média & $-660.178,83$ & 952,53 \\
\hline Desvio Padrão & 0,01 & 0,00 \\
\hline
\end{tabular}

Nota: * Valor Presente Líquido

Fonte: Resultados originais da pesquisa

Com base nos resultados da pesquisa, observa-se vantagem financeira em favor da frota própria, frente à frota terceirizada, dentro das premissas adotadas. Nessa análise, frente à frota terceirizada, a frota própria significa uma economia equivalente a 31,99\%.

As simulações efetuadas demonstram que com oscilações no mercado de veículos usados, caindo os valores de venda além de $35,63 \%$, ou quando reduzindo o valor de aluguel a $R \$ 955,62$, a terceirização de frotas passa a se mostrar interessante para a empresa.

No entanto, a frota própria, para continuar atrativa, depende da depreciação contábil, o que impacta diretamente na redução do IRPJ. Para a empresa manter essa opção, deve substituir sistematicamente seus veículos a cada cinco anos.

Com a economia em crise, o mercado de carros usados tende a se manter estável, pois a oferta de crédito abaixa e os juros tendem a subir, dificultando a compra de carros novos. O que favorece a opção de manter a frota própria.

Por outro lado, nessa pesquisa se utilizou apenas uma cotação, o que desfavorece a opção de terceirização. A empresa deve buscar outras opções no mercado, tanto quanto outras opções de modelo de veículos a serem locados, pois uma redução superior a $33,85 \%$ no valor do aluguel pode tornar a terceirização uma opção interessante, do ponto de vista financeiro. Porém deve ser levado em consideração outros fatores como idade dos veículos locados, capacidade de atendimento da empresa locadora, disponibilidade de veículos, etc. A falta de suporte da empresa parceira pode prejudicar o atendimento e consequentemente o resultado financeiro da empresa.

\section{Conclusão}

No caso de as premissas (valor mensal do aluguel dos veículos, taxa de correção contratual, Taxa Mínima de Atratividade e taxa de desvalorização) assumirem valores que acarretem um empate técnico, a opção de terceirização oferece um ganho de produtividade administrativa, que passa a ser um fator que deve ser observado, pois este gera um menor esforço corporativo para lidar com essa atividade, além do capital gerado nas vendas dos veículos entrar como uma alavancagem financeira na empresa.

\section{Referências}

Atkinson, A.A.; Banker, R.D.; Kaplan, R.S.; Young, M. 1997. Contabilidade Gerencial. Atlas, São Paulo, São Paulo, Brasil.

Banco Central do Brasil [BCB]. 2016. Correção de valores. Disponível em: < https://www3.bcb.gov.br/CALCIDADAO/public o/exibirFormCorrecaoValores.do?method=exibirFor mCorrecaoValores>. Acesso em: 09 nov. 2016.

Bodie, Z.; Merton, R.C. 1999. Finanças. Bookman, Porto Alegre, Rio Grande do Sul, Brasil.

Brito, F.S.; Duarte, J.M.; Soares, M.E.S. 2014.

Terceirização da frota de veículos oficiais: a experiência Mineira com a locação de veículos administrativos, operacionais e de representação. In: VII Congresso CONSAD de Gestão Pública, Brasília, DF, Brasil. Disponível em:

$<$ http://banco.consad.org.br/handle/123456789/10 $55>$. Acesso em: 09 nov. 2016. 
Cervo, A.L.; Bervian, P.A. 2002. Metodologia científica. Prentice Hall, São Paulo, São Paulo, Brasil.

Departamento Estadual de Trânsito de São Paulo [Detran]. 2016. Taxas / IPVA / DPVAT. Disponível em: < https://www.detran.mg.gov.br/veiculos/taxasipva-seguro-dpvat/seguro-transito-dpvat $>$. Acesso em: 08 nov. 2016.

Fundação Instituto de Pesquisas Econômicas [FIPE]. 2016. Preço médio de veículos. Disponível em: $<$ http://veiculos.fipe.org.br/>. Acesso em: 09 nov. 2016.

Gitman, L.J. 1997. Princípios de Administração Financeira. Harbra-Harper \& Row do Brasil, São Paulo, São Paulo, Brasil.

Instituto Brasileiro de Geografia e Estatística [IBGE]. 2016. Indicadores de preços. Disponível em: $<$ http://www.ibge.gov.br/home/estatistica/indicado res/precos/inpc_ipca/ipca-inpc_201610_1.shtm>. Acesso em: 07 nov. 2016.

Lankford, W.M.; Parsa, F. 1999. Outsourcing: a primer. Management Decision 37(4): 310-316.

Receita Federal. 2016 a. Instrução Normativa SRF N ${ }^{\circ}$ 130, de 10 de novembro de 1999. Estabelece a taxa de depreciação para fins contábeis. Disponível em: http://normas.receita.fazenda.gov.br/sijut2consulta/1 ink action? $\mathrm{visao}=$ anotado\&idAto $=14884 \# 795010$.

Acesso em: 07 nov. 2016.

Receita Federal. 2016 b. Instrução Normativa RFB no 1585, de 31 de agosto de 2015. Dispõe sobre o imposto sobre a renda incidente sobre os rendimentos e ganhos líquidos auferidos nos mercados financeiro e de capitais. Disponível em: http://idg.receita.fazenda.gov.br/acessorapido/legislacao/legislacao-por-assunto/imposto-derenda-pj. Acesso em: 07 nov. 2016.

Secretária de Estado de Fazenda. 2016. IPVA - Como se calcula o valor. Disponível em: http://www.fazenda.mg.gov.br/empresas/impostos /ipva/calculo.htm. Acesso em: 10 nov. 2016.

Schniederjans, M.J.; Schniederjans, A.M.;

Schniederjans, D.G. 2015. Outsourcing and Insourcing in an International Context. Routledge, Nova Iorque, Nova Iorque, Estados Unidos da América. 